\title{
‘Lei(a)tores” em processo coletivo e colaborativo no Quartas Dramáticas
}

André Luís GOMES ${ }^{1}$

Universidade de Brasília - UnB

Um público é uma junção de humanidade no que ela tem de melhor. (...) Eles vieram alimentar-se. Alimentar a inteligência, os olhos, o coração. Portanto, é verdade que, durante um momento, o público é o que há de melhor. É é preciso que se faça de tudo para que ele aumente" (A. Mnouchkine).

\section{Introdução}

Há alguns anos integro o GT Dramaturgia e Teatro $^{2}$ da ANPOLL (Associação Nacional de Pós-Graduação e Pesquisa em Letras e Linguística) com o objetivo, entre outros, de privilegiar o estudo do texto dramatúrgico em diálogo com pesquisadores de diferentes instituições de ensino. Esse diálogo tem se revelado extremante produtivo na medida em que pesquisas conjuntas são realizadas. Conheci pesquisadores de diferentes regiões brasileiras e me deparei com uma quantidade crescente de pesquisas sobre teatro, que me revelaram ou resgataram autores, textos e grupos teatrais. Motivado pelas pesquisas do GT, criei o Grupo de estudos em Dramaturgia e Crítica Teatral (GDCT) na Universidade de Brasília e realizamos, entre 2007 e 2009, pesquisa sobre a publicação de textos teatrais contemporâneos, que resultou na organização do livro Leio teatro - dramaturgia brasileira contemporânea, leitura e publicaşão.

Constatamos, a partir da pesquisa realizada, que o estudo da dramaturgia ocupa pouco espaço nas grades curriculares dos cursos de Letras e, mesmo nos cursos de Artes Cênicas, as disciplinas cujo conteúdo programático privilegiam a leitura e análise de peças teatrais têm diminuído significativamente. Além disso, constata-se que, no ensino básico e médio, a leitura do texto teatral é muito pouco estimulada. Basta, como comprovação, abrirmos os livros didáticos para chegarmos à conclusão de que os alunos, geralmente, saem do ensino médio com poucas informações sobre o teatro e leem, geralmente, peças de Gil Vicente, trechos da comédia de Martins Pena e são informados da revolucionária montagem de Vestido de noiva, de Nelson Rodrigues, em 1943. Há, entretanto, iniciativas

\footnotetext{
1 Professor do Departamento de Teoria Literária e Literaturas e do Programa de Pós-Graduação em Literatura da Universidade de Brasília. Doutor em Literatura pela FFLCH-USP. Autor dos livros Marcas de nascença a contribuição de Gonçalves de Magalhães para o teatro brasileiro, Clarice em cena: as relações entre Clarice Lispector e o teatro. Organizador do livro Leio teatro. E-mail: andrelg.unb@gmail.com.

2 Maiores informações sobre o GT DRAMATURGIA E TEATRO podem ser obtidas no seguinte endereço eletrônico www.gtdramaturgiaeteatro.com.br.
} 
que estimulam e/ou obrigam a leitura de peças teatrais como as listas de leituras obrigatórias de vestibulares e a transmutação de textos teatrais para o cinema e a televisão.

Essas constatações provocaram em mim alguns questionamentos, afinal, como explicar que, em um país em que a telenovela preenche as noites dos telespectadores com altos índices de audiência, o aluno do ensino básico e médio não seja estimulado a conhecer/ler textos teatrais e, nos cursos de Letras e Artes Cênicas, disciplinas voltadas para a análise de textos dramatúrgicos e para a História do Teatro têm ocupado cada vez menos espaço nas grades curriculares e, nesses cursos, não há nenhum trabalho efetivo na formação de novos dramaturgos? Não estaríamos mantendo o círculo de pessoas interessadas pelo Teatro e, em sentido mais amplo, deixando de ampliar a formação de cidadãos com aptidões culturais ao optarmos, nos cursos de Artes Cênicas, pela formação de atores, atrizes e diretores com pouco conhecimento da dramaturgia e da História do teatro? Por que, nos cursos de Letras, poucas são as disciplinas voltadas para o estudo, por exemplo, do Teatro Brasileiro, quando sabemos da presença constante dessa arte em momentos decisivos de nossa História e para a formação de nossa literatura a ponto de Antonio Candido, no prefácio da primeira edição da Formação da Literatura Brasileira, afirmar:

O preparo deste livro, feito por etapas, de permeio a trabalhos de doutra especialidade, no decorrer de muitos anos, obedeceu a um plano desde logo fixado, por fidelidade ao qual respeitei, na revisão, certas orientações que, atualmente, não teria escolhido. Haja vista a exclusão do teatro, que me pareceu recomendável para coerência do plano, mas importa, em verdade, num empobrecimento, como verifiquei ao cabo da tarefa (1993, p. 12) (grifo nosso).

A partir desses questionamentos e constatações, o Grupo de estudos em Dramaturgia e Crítica Teatral (GDTC) tem realizado algumas pesquisas sobre a leitura de peças teatrais e decidiu, em 2010, propor o projeto Quartas Dramáticas, em que a leitura fosse pensada a partir de uma prática cênico-literária-midiática. Iniciamos, portanto, o projeto com os seguintes objetivos: divulgar as peças teatrais e seus respectivos dramaturgos, motivar a leitura enquanto prática cênica e integrar ao projeto ações midiáticas e linguagens inovadoras. Assim, no Quartas Dramáticas, as leituras encenadas são apresentadas para a comunidade acadêmica e para o público em geral sob a coordenação de professores/pesquisadores com a participação de graduandos e pós-graduandos dos Departamentos de Teoria Literária e Literaturas (TEL), de Línguas Estrangeiras e Tradução (LET) e de Artes Cênicas (CEN) da Universidade de Brasília. Além disso, mantemos o 
blog Quartas Dramáticas ${ }^{3}$ com o objetivo de dar visibilidade ao projeto e disponibilizar ao internauta - entendendo-o como um agente multi-mídia - fotos, trechos em vídeo das leituras cênicas, textos teatrais, resenhas críticas, informações sobre os dramaturgos, ampliando possibilidades de diálogo, através de postagens e envio de e-mails entre interessados e de forma mais globalizada.

Enquanto exercício prático, o objetivo é observar se a leitura cênica de peças teatrais exige habilidades específicas tanto daquele que ensina a ler quanto daquele que lê o texto teatral, considerando todas as possíveis definições de "leitura". Esses objetivos foram se desdobrando na medida em que as apresentações das leituras cênicas trouxeram outros questionamentos, evidenciaram outros resultados e provocaram outras reflexões que passamos a dividir com leitores deste artigo.

\section{Leiatores em leituras cênicas}

Adjetivamos as leituras, apresentadas no Quartas Dramáticas, de "cênicas", uma vez que as apresentações são realizadas por grupos de alunos, coordenadas, geralmente, por um professor/pesquisador com uma movimentação cênico-espacial e com a utilização de outros elementos/recursos cênicos como figurino, cenário e iluminação. Há, portanto, uma preocupação em trabalhar outras dramaturgias, tais como a dramaturgia dos objetos, da música, das sonoridades e, principalmente, a do ator.

Nesse trabalho, outro detalhe importante que caracteriza a leitura cênica é o uso cênico do texto impresso: o texto deve ser pensado também cenicamente, ou seja, o papel impresso transforma-se em um objeto cênico. Portanto, ele deve ganhar função cênica e essa funcionalidade depende, obviamente, da criatividade do grupo na construção da leitura. Por isso, há grupos que utilizam o texto de forma, digamos, tradicional, ou seja, os atores estão o tempo todo com a peça inteira nas mãos, mas outros optam por espalhar fragmentos do texto pelo palco, dispondo-os cenicamente. Várias são as formas de lidar com o texto cenicamente e é muito comum se estabelecer uma relação teatral com texto, incluindo-o, por exemplo, na dramaturgia do corpo e da cena.

\footnotetext{
${ }^{3}$ Endereço do blog: www.quartasdramaticas.blogspot.com.
} 


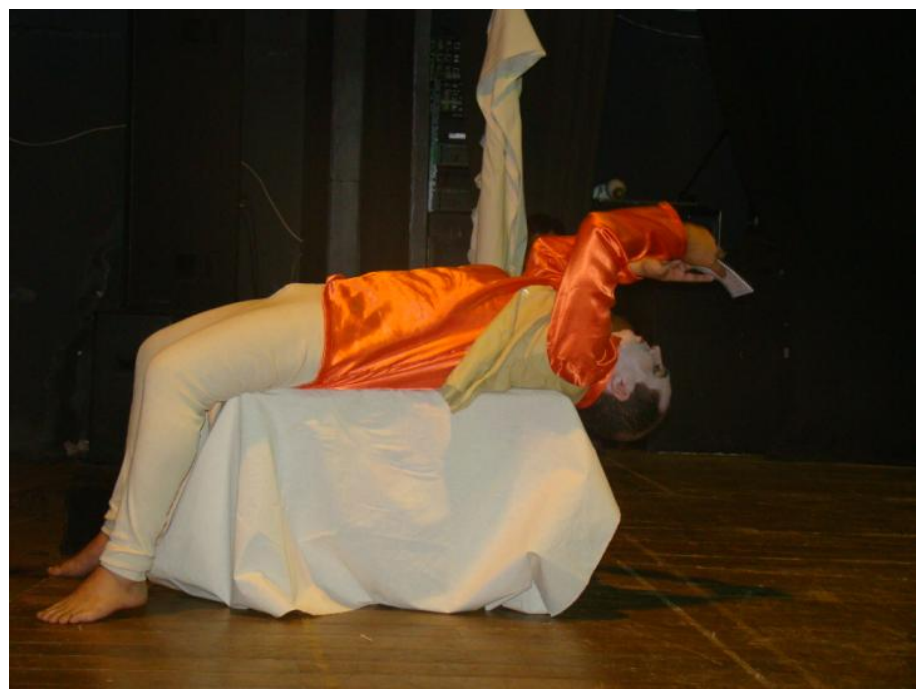

Foto 1: Leitura cênica da peça As cidades invisiveis, de Renata Pallottini, adaptação do romance homônimo de Ítalo Calvino. Em destaque o leiator Augusto Rodrigues.

$\mathrm{Na}$ experiência prática do ator/atriz, chegamos à conclusão que interpretar e ler cenicamente exige uma técnica específica, afinal, o ator tem que dosar a interpretação do seu papel - com toda a carga emocional que isso exige - com a capacidade de ler o texto, isto é, saber onde inicia e termina sua fala num jogo que exige o olho no olho entre os atores e, ao mesmo tempo, capacidade de lidar conscientemente com o texto escrito. $\mathrm{O}$ leitor-ator deve balizar sua capacidade de interpretar com a de ler, ou seja, saber quando deve virar uma página e em que momento deve deixar o texto para uma ação corporal em que "segurar o texto impresso" pode comprometer sua dramaturgia corporal.

Com todas essas peculiaridades técnicas, passei a denominá-lo de leiator ou leiatriz, uma vez que a leitura deve associar as qualidades cênicas do ator/atriz às habilidades do leitor que detém conhecimento do texto e das nuances das falas das personagens. Com esse neologismo - leiator - estou de certa forma afirmando que o texto teatral ganha muito quando é lido por um ator/atriz ou por um leitor que compreenda as características e intenções das personagens, estude as entonações das falas, perceba a musicalidade do texto e situe a sua personagem na completude da ação dramática do texto teatral. (foto 2) 


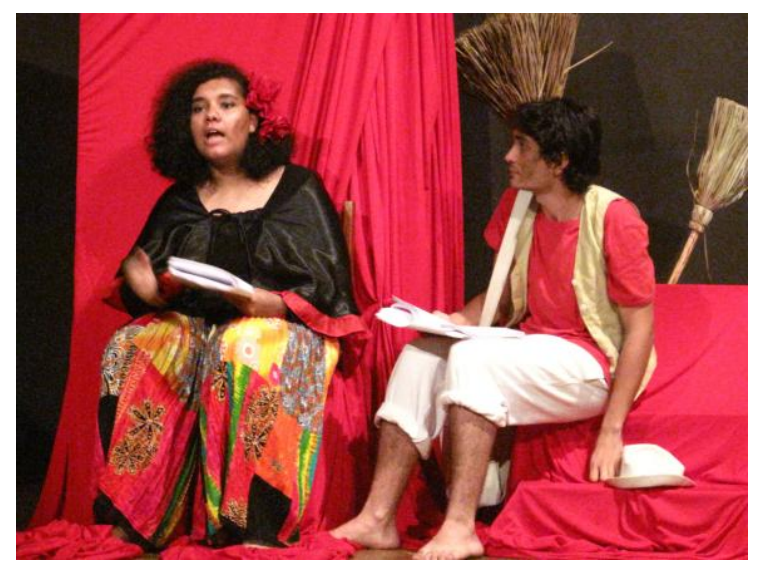

Foto 2: Laila Vieira e Marcelo Paiva, alunos do curso de Letras, na leitura cênica da peça teatral As velhas, de Lourdes Ramalho.

Na leitura cênica, o leiator deve criar a cena com o texto e não a partir dele, ou seja, o que se pretende é uma construção conjunta da cena com o texto em um processo que associa a dramaturgia do texto, da cena, do corpo e da voz. Não há a preocupação, por exemplo, de ler as rubricas/didáscalias na construção da leitura cênica. Pelo contrário, busca-se o apagamento da voz do autor para evidenciar outras vozes, como afirma Anne Ubersfeld:

Primeiro traço distintivo na escritura teatral: ela nunca é subjetiva, na medida em que, por sua própria vontade, o autor recusa-se a falar em seu próprio nome; a parte textual cujo sujeito é o autor é constituída apenas pelas didascálias. O diálogo é sempre a voz de um outro - e não somente a voz de um outro, mas de muitos outros (UBERSFELD, 2005, p. 7).

A partir dessas outras vozes é que a rigidez das fronteiras entre a dramaturgia do texto e a dramaturgia da cena podem então ser flexibilizadas, uma vez que a relação entre o texto e a cena pode ser estabelecida através de uma troca construtiva/colaborativa e não pela imposição de um sobre o outro. Nesse sentido, há, obviamente, um jogo sucessivo de poder que se estabelece entre essas "vozes", por isso é necessário entender, como ressalta Foucault (1979, p. 8), que o poder "não pesa só como uma força que diz não, mas que de fato ele permeia, produz coisas, induz ao prazer, formas de saber, produz discurso". Na montagem de uma leitura cênica, essas vozes podem ser alternadas e/ou simultâneas e a supremacia do texto sobre os outros elementos da cena, diluída.

Por exemplo: Quando um grupo de alunos se propôs a encenar a leitura de um texto de Nelson Rodrigues sem ainda ter decido qual seria a peça rodriguiana, propus improvisações a partir das características do teatro de Nelson Rodrigues. O diálogo, portanto, se construiu, articulando o repertório de conhecimento que os alunos tinham das 
características do teatro de Nelson Rodrigues com as improvisações e, finalmente, com o texto escrito. Assim, buscamos associar dramaturgia com a encenação, privilegiando um trabalho simultâneo entre os três níveis de dramaturgia propostos por Eugenio Barba: a dramaturgia orgânica ou dinâmica; dramaturgia narrativa e a dramaturgia das mudanças de estado ou evocativa.

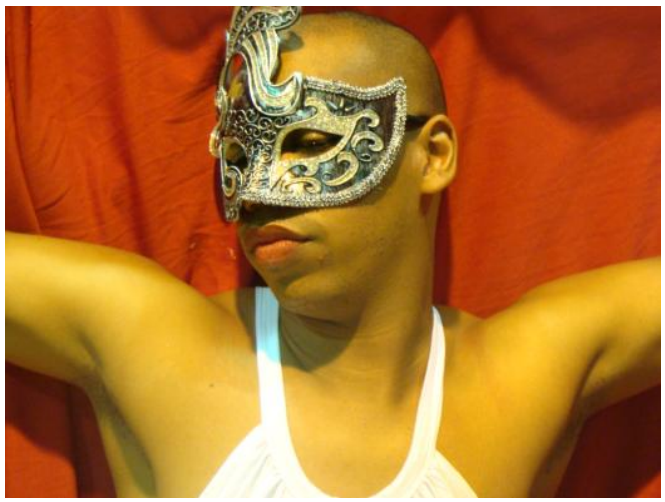

Foto 3: João Paulo em cena da leitura da peça $A$ serpente, no papel da "Crioula".

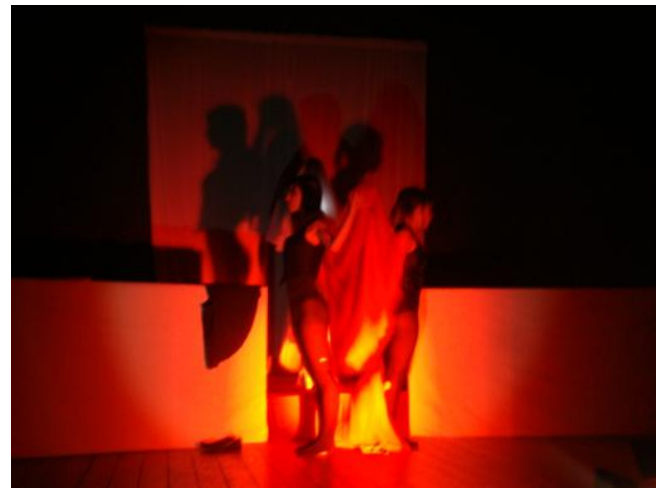

Foto 4: A serpente, de Nelson Rodrigues.

\section{Da leitura analítica à leitura cênica ou vice-versa}

Estamos na quarta edição do Quartas Dramáticas e já foram lidas cenicamente 21 peças teatrais ${ }^{4}$. No entanto, a teatralidade das leituras nem sempre foi a mesma: leituras foram apresentadas em que o texto já estava quase decorado e os outros elementos cênicos - figurino, cenário, sonoplastia - foram utilizados numa quase montagem teatral; em outras, grupos apresentaram leituras sem movimentação cênica, mas investiram na construção das personagens através da interpretação dos atores/atrizes e da caracterização das personagens com figurinos especialmente pensados para a leitura cênica.

\footnotetext{
${ }^{4}$ Já foram encenados os seguintes textos teatrais: Os sonhos do infante, de Alama Oliveira; Quarto de empregada, de Roberto Freire; Antígona, de Sófocles; Infieles, de Marco Antonio de La Parra; Electra no circo, de Hermilo Borba Filho; Epistola aos jovens atores, de Olivier PY; A farsa da boa preguiça, de Ariano Suassuna; Catharsis, de Gustave Akakkpo; Agreste, Newton Moreno; As velhas, de Lourdes Ramalho; Os gatos morrem no asfalto, de André Amaro; Tinta gatos e um cão envenenado, de Geraldo Lima; Entre quatro paredes, de Jean Paul Sartre; Carta aos atores, de Valère Novarina; A serpente, de Nelson Rodrigues; O visitante, de Hilda Hilst; Cidades Invisiveis, de Renata Pallottini; O livro de Jô, de Luiz Alberto de Abreu (Teatro da Vertigem); Cabaré da Raça, Marcio Meirelles e Chica Carelli (Bando de Teatro Olodum); Mutirão em novo sol, de Augusto Boal e Nelson Xavier.
} 


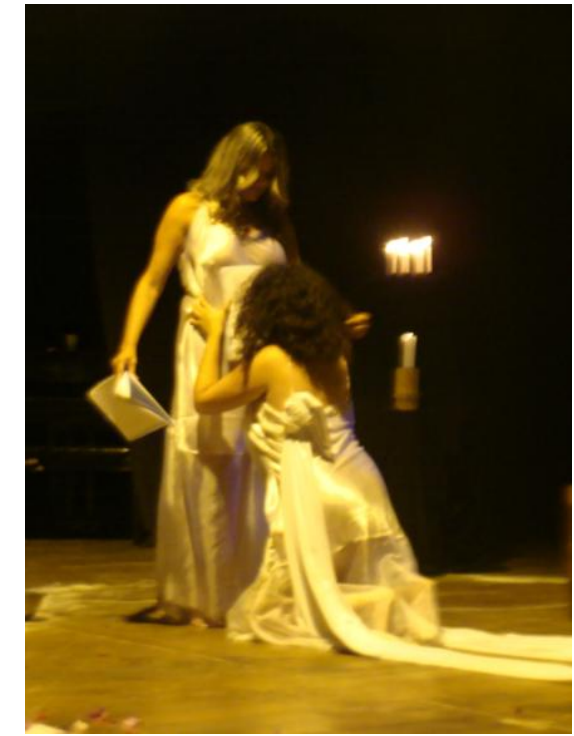

Figura 5: Débora Andreá e Júlia Capdeville na leitura da peça $O$ visitante, de Hilda Hilst.

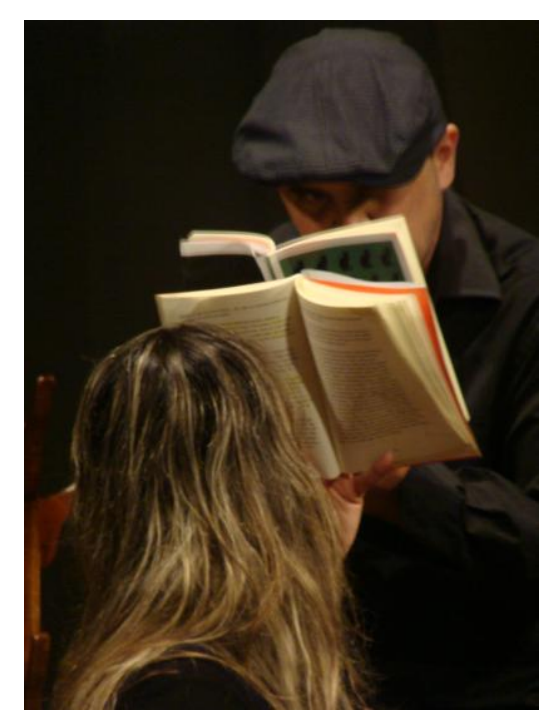

Figura 6: Débora Andreá e Augusto Rodrigues em Trinta gatos e um cão envennado, de Hilda Hilst.

É preciso enfatizar que a leitura cênica pressupõe a encenação da leitura do texto, tendo em mente a definição dicionarizada do termo: "Numa ampla acepção, o termo encenação designa o conjunto de meios de interpretação cênica: cenário, iluminação, música e atuação" (PAVIS, 1999, p. 122). A partir da observação das leituras apresentadas, notei que esses meios de interpretação são, geralmente, pensados e criados pelos integrantes do grupo em um processo colaborativo e coletivo. O processo colaborativo e coletivo resulta, certamente, do pouco tempo que os grupos têm para montar a leitura cênica e da pouca experiência de alguns integrantes dos grupos, às vezes, formados apenas com alunos do curso de Letras, que participam inclusive da tradução do texto. Nesse sentido, vale ressaltar que os professores de diferentes disciplinas de Letras e de Artes Cênicas incluem a leitura cênica no planejamento semestral das disciplinas e o trabalho é desenvolvido de acordo com suas especificidades e objetivos. O que se observa, portanto, é a função prática da atividade proposta, uma vez que os alunos trabalham tendo um objetivo prático: apresentar para a comunidade os resultados de sua atividade enquanto intérpretes do texto teatral, seja como ator/atriz, iluminador, cenógrafo ou sonoplasta.

Como professor do curso de Letras, o que efetivamente observo é a transmutação das análises dos textos, fundamentadas, na maioria das vezes, em teorias literárias, em práticas cênicas, em que determinado objeto acentua uma palavra, em que uma luz evidencia metáforas contidas no texto, em que a impostação de uma fala muito diz sobre as características da personagem e imagens são construídas e desconstruídas no palco ressaltando detalhes do texto ou construindo outros. 
Antonio Candido, quando discute o "direito à literatura", destaca alguns valores dos textos literários e suas relações com a sociedade e ressalta que "as palavras organizadas são mais do que a presença de um código: elas comunicam sempre alguma coisa, que nos toca porque obedece a uma certa ordem", mas adverte:

Quando digo que um texto me impressiona, quero dizer que ele impressiona porque sua possibilidade de impressionar foi determinada pela ordenação recebida de quem o produziu. Em outras palavras usuais: o conteúdo só atua por causa da forma, e a forma traz em si, virtualmente, uma capacidade de humanizar devido à coerência mental que pressupõe e que sugere. (...) Toda obra literária pressupõe esta superação do caos, determinada por um arranjo especial das palavras e fazendo uma proposta de sentido (CANDIDO, 1995, p. 246).

Creio que a função do estudioso do texto literário seja desvendar esse "arranjo especial das palavras", evidenciar para o leitor mais desatento a habilidade do autor em concebê-lo e apontar as propostas de sentido que há no texto. Transmutar um texto teatral em leitura cênica é operar com as mesmas ferramentas do estudioso em literatura, mas tendo em vista outro suporte e os meios cênicos.

Frye, em Mito, ficção e deslocamento, também reconhece no texto literário algo que impressiona e inclui as peças teatrais entre as obras ficcionais nas quais se pode reconhecer o que ele chama de "persuasão de continuidade":

\footnotetext{
Mas na experiência direta da literatura, que é algo distinto da crítica, temos consciência daquilo que podemos chamar de persuasão de continuidade - o poder que nos faz continuar virando as páginas de um romance e que nos segura nas nossas cadeiras de teatro. (...)

A continuidade de uma obra de literatura existe em diferentes níveis rítmicos. No primeiro plano, cada palavra, cada imagem, até mesmo cada som feito audível ou inaudível pelas palavras, faz sua contribuição ao movimento total. (...) (FRYE, 2000, pp. 28-9).
}

Quando um grupo ou um encenador decide transmutar um texto para o palco, ele deve desvendar a "persuasão de continuidade" deste texto e trabalhar cenicamente com os níveis de continuidade que ele guarda intrínseca e extrinsecamente. E essa transmutação resulta em uma transcriação na medida em que esse outro suporte - o palco - exige uma boa dose de criatividade do encenador/grupo teatral.

Se o trabalho de análise de um texto literário se constrói a partir de teorias teatrais e ela se torna mais densa e criativa quando reflexões sobre o texto são compartilhadas entre os alunos, o mesmo pode ser dito para a construção cênica da leitura, resguardadas suas especificidades. 
Como já dissemos, há vários leitores envolvidos nos diferentes momentos do Quartas Dramáticas e com diferentes objetivos:

1. O leitor do texto teatral que tem por objetivo conhecê-lo e analisá-lo. Este leitor, às vezes, nunca esteve em um teatro para assistir a uma encenação e sua única experiência com a representação cênica de um texto é a telenovela;

2. O leitor que tem por objetivo transmutar o texto em um a leitura cênica. Portanto, seu objetivo é transcriar aquele "arranjo especial de palavras e propostas de sentido" em realização cênica;

3. O leitor-espectador que assiste à leitura cênica sem ter lido antes o texto;

4. O leitor-espectador que assiste à leitura cênica, mas já conhece o texto;

5. O leiator ou leiatriz que lê o texto para construir sua personagem;

6. O leitor-encenador que vê o texto na totalidade de sua dimensão cênica;

7. O leitor-destinatário pelo o qual o mercado editorial está sempre interessado.

Certamente, muitos outros leitores poderiam ser elencados. Para cada uma desses leitores, a recepção do texto é balizada por seus objetivos e interesses pessoais e mais imediatos, mas, no momento da leitura cênica, eles compõem "um círculo mágico que se forma entre público e encenadores (um conceito amplo que passou a compreender também os atores) e que, nesse sentido, o público é também parte da encenação" (AGUIAR, 2007, p. 454). Nesse círculo, espera-se que esses leitores atuem de forma ativa e reflexiva para além da leitura cênica e em direção à sociedade.

\section{BIBLIOGRAFIA CITADA:}

BARBA, Eugenio. Queimar a casa. Origens de um diretor. São Paulo, Perspectiva, 2010.

CANDIDO, Antonio. Formação da literatura brasileira. vol. 1. $7^{a}$ ed. Belo Horizonte, Editora Itatiaia, 1993.

FÉRAL, Josette. Encontros com Ariane Mnouchkine: erguendo um momento ao efêmero. Tradução de Marcelo Gomes. São Paulo, Editora Senac São Paulo, 2010.

FERNANDES, Sílvia. Teatralidades contemporâneas. São Paulo, Perspectiva: FAPESP, 2010.

FRYE, Northrop Frye. Fábulas de identidade: ensaios sobre mitopoética. Tradução de Sandra Vasconcelos. São Paulo, Nova Alexandria, 2000.

GOMES, André Luis (org.). Leio Teatro. São Paulo, Horizonte, 2010.

PAVIS, Patrice. Dicionário de teatro. Tradução sob a direção de J. Guinsburg e Maria Lúcia Pereira. São Paulo, Perspectiva, 1999.

UBERSFELD, Anne. Para ler o teatro. São Paulo, Perspectiva, 2005.

WILLIAMS, Raymond. Palavra-chave - um vocabulário de cultura e sociedade. Tradução de Sandra Gardini Vasconcelos. São Paulo, Boitempo, 2007. 
Abstract: In 2010 we started the extension project "Quartas Dramáticas" in which are displayed readings scenic dramas, generally acted by students of Literature and Performing Arts under the supervision of Universidade de Brasília'teachers. In this paper, our intention is to relate this experience and to analyze it as a scenic-literary procedure and a collective and collaborative realization, proposing a reflection between the analytical reading and theatrical reading by literary-theater texts.

Keywords: Quartas Dramáticas; theatrical reading; dramaturgy of the text; dramaturgy of the scene. 